\title{
Honing healthcare leaders' competence and attitudes equals facility-level delivery
}

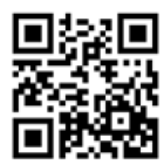

Just when you thought there was enough evidence to give up on our public and private healthcare sectors ever partnering to deliver quality, affordable care to a critical mass of South Africans - National Health Insurance (NHI) notwithstanding - along come several potentially game-changing training initiatives.

Izindaba can now reveal that at least three healthcare facility management and training courses are already impacting on until recently woeful public sector facility leadership. They are providing vital support to hospital, clinic and community healthcare workers, often highly clinically skilled but under-equipped and struggling to manage the day-to-day running of their facilities

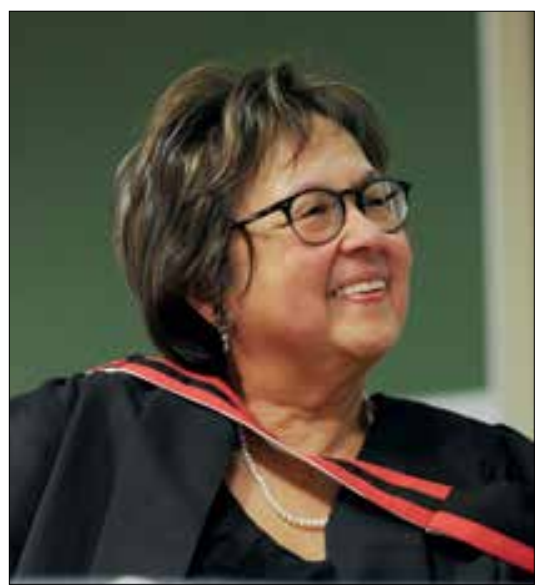

Prof. Marion Jacobs.

It all (officially) began in 2012 with a national audit of public healthcare facility operational managers. Under-qualified and/or underperforming chiefs were either redeployed or slotted into existing 'upgrade' courses. Former Dean of Medicine at the University of Cape Town, Prof. Marion Jacobs, was appointed by national health minister $\mathrm{Dr}$ Aaron Motsoaledi to set up the Academy of Leadership and Management of Health, training student healthcare managers and up-skilling existing healthcare facility CEOs, pulling together and standardising numerous existing programmes into a single, needs-appropriate 'virtual institution', and drawing on the best available expertise. Long before this however (in 2005), the South African Medical Association (SAMA)'s highly successful Foundation for Professional Development (FPD) was running two externally funded and fully subsidised courses: an advanced certificate in health management (partnering with Yale University) - a virtual hospital management mini-MBA - and an entry-level certificate in healthcare management, which has churned out 5000 trainees to date. Both are distance education courses with face-to-face student support tutorials in the cities they work in, focusing on monitoring and evaluation, project management, communication skills, human resources and resource mobilisation. Anton le Grange, head of the FPD's Quality Assurance Academic Program Development and Management Training, has several uplifting stories that strongly illustrate the impact their courses are having, particularly in the public sector. 'Initially it was difficult to measure, so we started following our students to see if the knowledge they were receiving was having results.

However, if there is no management or leadership expertise to push the process forward, it stalls. COHSASA spokesperson Marilyn Keegan said there were 'numerous experiences' of hospitals being given standards, shown how to use them and encouraged to use the tools provided, 'but nothing happens'. 'The missing factor is a good manager or leader who understands why using standards to measure what does and does not happen in a healthcare facility represents the best of all worlds: he/ she can see what is wrong and do something about it.'

\section{The power of one}

One doctor running a primary healthcare clinic in the Sekukhune district of Limpopo Province chose to begin monitoring and evaluating the National Core Standards audit of his facility by the national Office for Healthcare Standards Compliance (OHSC) - part of the work-up towards setting minimum healthcare delivery standards in advance of the ambitious NHI implementation. His clinic initially received a $64 \%$ score $(70 \%$ being the minimum threshold for norms and standards). He set to work implementing the FPD training he was concurrently receiving as part of his yearlong studies, and by October 2014 (with his graduation due in July 2015), his clinic scored $80 \%$ - a direct result of his interventions. Says Le Grange: 'Most of our students come back and say they find the project management and monitoring and evaluation aspects the most useful. This was exactly why we started the courses (currently 900 students enrolled, equally divided between courses and all fully subsidised from among 3000 annual applications). $\mathrm{He}$ adds: 'You have doctors and nurses with excellent clinical skills but pushed into running a facility or unit without any managerial experience. We teach them how to be leaders, what a supervisor is, how to present yourself. They also come away talking better and more effectively to their staff and to patients.

\section{Identifying and plugging the gaps}

Then cut to the private equivalent of the OHCSC - a veteran quality assurance outfit, the Council for Healthcare Service Accreditation of South Africa (COHSASA). Based in Pinelands, Cape Town, COHSASA has been beavering away quietly for the past 18 years, teaching healthcare workers how to cost-effectively monitor improvements using quality improvement methods, internationally accredited standards and a webbased information system. It has accredited 600 healthcare facilities throughout Africa (hundreds of them in the South African (SA) public healthcare sector) and regularly audits and supports facilities to help them stay on track and retain accreditation. Its forte is in improving patient safety and quality of care by identifying deficiencies, guiding interventions and monitoring progress, and providing quality improvement plans. Its founder and director, Prof. Stuart Whittaker, sits on the board of the OHSC, providing invaluable input and guidance to the current national core standards process that has completed audits of $20 \%$ of all public sector hospitals so far.

Patch into COHSASA's work a recent academic innovation at Stellenbosch University (SU). Headed by Dr Jurgen Seifert, course co-ordinator of the new Executive Development for Healthcare Leaders on the SU campus at Bellville Park, the programme was born out of filling a pragmatic need in COHSASA's work. COHSASA's baseline 
evaluation of facilities identifies where there are gaps in providing safe and quality care. Senior hospital managers and unit leaders are supplied with a clear blueprint of how to address these gaps, prioritising the most critical ones. However, if there is no management or leadership expertise to push the process forward, it stalls. COHSASA spokesperson Marilyn Keegan said there were 'numerous experiences' of hospitals being given standards, shown how to use them and encouraged to use the tools provided, 'but nothing happens'. 'The missing factor is a good manager or leader who understands why using standards to measure what does and does not happen in a healthcare facility represents the best of all worlds: he/she can see what is wrong and do something about it.'

Siefert said his course provided the pragmatic know-how on what it takes to be a leader. 'How do the receptionists, radiotherapists, ordinary doctors, get themselves into a leadership mindset? How do they apply situational awareness that goes beyond protocols, check-lists and computer programs to apply considered human judgment?' he asks. With a $\mathrm{PhD}$ in aviation, Seifert says the health sector is 'about 40 years' behind aviation in applied human judgement backed by technology. 'You need to build an acute awareness of what needs to be done - and have excellent "flying skills", he says, citing the instant decision of the pilot who impeccably landed his plane in the icy Hudson River after his engine ingested a flock of geese, forcing a stall at low altitude. Seifert said continuous training and upskilling was 'essential' in healthcare to prevent leaders 'falling back on bad habits.' 'You need to stay in the forefront of what's happening in your operating environment. We're moving from transactional management to transformational leadership. It's all about attitude and outlook complementing appropriate skills, he added.

\section{He set to work implementing} the FPD training he was concurrently receiving as part of his year-long studies, and by October 2014 (with his graduation due in July 2015), his clinic scored $80 \%$ - a direct result of his interventions.

\section{Leading under}

'conditions of complexity and uncertainty'

The primary aim of the 5-day Stellenbosch course is 'to explore, analyse and unpack the advanced topics in current leadership thinking as it applies to the healthcare system'. The course will focus on the competence (knowledge, skills and attitudes) necessary for an organisational leader to function 'under conditions of complexity and uncertainty'. Case studies from the students' own facilities will be used to develop solutions to problems, and a full assignment is expected to be handed in a month after completing the course.

So what is the initial evidence that the combination of these and other similar courses are beginning to improve healthcare delivery in South Africa? A recent survey of five critical patient care areas in the public sector conducted by an agent for the OHCSC showed a $40.1 \%$ leap in 'positive caring attitudes' held by public health facility staff members (from $30 \%$ to the $70 \%$ threshold) in the past 2 years. This was followed by a $27 \%$ improvement in patient safety and security (34\% to $61 \%$ ), with availability of medicines and supplies increasing by $12 \%$ ( $54 \%$ to $65.5 \%)$, this last improvement a hopeful sign that woefully inadequate supply management systems, corruption and theft might actually be yielding slightly to a raft of new National Department of Health initiatives.

\section{Chris Bateman}

chrisb@hmpg.co.za

S Afr Med J 2015;105(2):85-86.

DOI:10.7196/SAMJ.9316 